\title{
METODE PEMBELAJARAN CLASS DISCUSSION DAPAT MENINGKATKAN KUALITAS SPEAKING (BAHASA INGGRIS) TERHADAP MAHASISWA/PESERTA DIDIK
}

\author{
J. Anhar Rabi Hamsah Tis'ah \\ Janharqisty@gmail.com \\ (Dosen Fakultas Agama Islam Universitas Muhammadiyah Tangerang)
}

\begin{abstract}
Abstrak:
Keterbatasan wadah untuk mengeksplorasi speaking skill bagi seseorang yang mau mengasah keahliannya dalam bidang speaking (berbicara) menggunakan bahasa Inggris sangat mempengaruhi proses tebentuknya pembiasaan tersebut jika tidak adanya wadah untuk melatih diri. Dalam hal ini class discussion sangat berfungsi untuk menunjang keahlian speaking seseorang guna mencapai kualitas yang lebih baik.
\end{abstract}

\section{Kata kunci : Class Discussion, Kualitas, Speaking.}

\section{A. Pendahuluan}

Manusia merupakan makhluk sosial yang saling berinteraksi satu sama lainnya, saling berkomunikasi dan berbagi informasi, dalam hal ini manusia akan berbaur dengan sesamanya yang berbeda sifat, pola pikir, karakter dan adat istiadat, bahkan dalam cara berbicara dan bertutur kata, ia akan mendengar perkataan yang baik juga akan mendengar perkataan yang buruk, maka untuk mengontrol hal ini Allah menurunkan sebuah ayat yang menjadi kaidah umum dalam berbicara:

$$
\text { وَقُولْوْا لِلنَّاسِ حُسنْنَا }
$$

"Serta ucapkanlah kata-kata yang baik kepada manusia"1

Ada beberapa ayat yang senada dengan bunyi ayat di atas baik secara langsung atau tidak langsung, di antaranya adalah firman Allah:

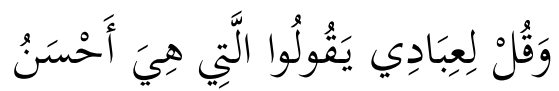

"Dan Katakanlah kepada hamha-hambaKu: "Hendaklah mereka mengucapkan Perkataan yang lebih baik (benar),"2

Dari beberapa uraian ayat Al-qur'an diatas, kita bisa menilai betapa pentingnya beriniteraksi/berbicara terhadap lawan bicara harus dengan aturan-aturan atau adab yang biak kepada yang lebih muda umurnya, sesama umur, bahkan kepada yang lebih tua agar kualitas pembicaraan masih dalam norma dan etika yang ada.

Dewasa ini banyak fenomena negatif yang terjadi dalam hal berkomunikasi, dikarenakan kurang mengertinya bagaimana berkomunikasi dengan baik mungkin ketika dalam kondisi emosioanal yang sedang tinggi atau dalam kedaan tenang, baik secara langsung, contohnya ketika sedang berdikusi/berdialog, face to face, serta secara tidak langsung seperti melalui media-media saat ini yang akhirnya bisa memicu kegaduhankegaduhan yang tidak berarti.

${ }^{1}$ QS. Al-Baqoroh: 83

${ }^{2}$ QS. Al-Isro: 53 
Tidak sedikit masyarakat yang mengabaikan hal-hal yang harus dijaga ketika sedang berkomunikasi antar sesama. Sehingga tidak sedikit pula generasigenerasi Bangsa yang terbiasa mendengar kata-kata kasar/tidak sopan bahkan hoax (tidak benar) yang seharusnya tidak perlu diutarakan, tetapi karna faktor emosi dan pengaetahuan memilih kata/bahasa yang masih kurang akhirnya menjadi kebiasaan dalam kehidupan sehari-hari dan berimbas negative bagi penerus bangsa ini. Sama halnya ketika kita sedang bersidkusi dalam forum formal dan nonformal, yang diperlukan tidak hanya pengetahuan akademik/kognitif saja, melainkan faktor afektifnya juga harus diutamakan sehingga secara psikomotorik hasilnya bagus dan berkualitas khususnya bagi Mahasiswa/ Peseta didik dimasa depan dan bermanfaat untuk kedepannya.

Sehingga nilai norma, hukum dan budaya khususnya dalam hal berkomunikasi, berdialog dan berdikusi di negara Indonesia ini memiliki nilai yang lebih bagus dibandingkan negara lain. Oleh sebab itu, metode class discussion sangat efektif dalam membiasakan diri untuk melatih kemampuan berbicara (speaking), berdiskusi dan berkomunikasi bagi Mahasiswa/Peserta didik agar budaya Indonesia tetap terjaga bahkan bisa menjadi rujukan dan barometer dunia. Dan akhirnya budaya leluhur Indonesia masih terjaga untuk generasi selanjutnya dan semakin rekat serta bermartabat baik diranah nasional maupun internasional.

\section{B. Pembahasan}

\section{Pengertian Diskusi kelas}

Diskusi kelas adalah suatu bentuk percakapan secara ilmiah yang dilakukan beberapa inidvidu dalam kelompok, dimana setiap anggota kelompok atau kelompok yang berbeda terjadi proses saling tukar pendapat masalah tertentu dan berusaha untuk memecahkannya. Hal yang perlu diperhatikan dalam melaksanakan diskusi di dalam kelas, diantaranya ialah mengikut sertakan seluruh mahasiswa, pembicaraan jangan didominasi oleh mahasiswa tertentu, ketertiban perlu dijaga, debat perlu terarah, setiap peserta mendapatkan kepercayaan yang sama, dan tarekhir adalah menjaga etika sopan santun, baik terhadap teman dan Dosen.

Menurut kamus besar bahasa indonesia, diskusi di artikan sebagai suatu pertemuan ilmiah untuk bertukar pikiran mengenai sustu masalah. Diskusi biasanya membahas suatu topik yang menjadi perhatian umum dimana masingp-masing anggota kelompok mempunyai kesempatan yang sama untuk bertanya dan memberikan pendapat.

Metode pembelajaran diskusi adalah suatu cara penyajian bahan pelajaran dimana guru memberi kesempatan kepada para Mahasiswa (kelompok-kelompok Mahasiswa) untuk mengadakan pembicaraan ilmiah guna mengumpulkan pendapat, membuat kesimpulan, atau menyusun berbagai alternatife pemecahan suatu masalah. Dengan demikian metode pembelajaran diskusi dapat dikatakan sebagai metode partisipatif dan juga termasuk metode kooperatif.

Diskusi kelompok merupakan suatu proses bimbingan dimana murid-murid akan mendapat suatu kesempatan untuk menyumbangkan pemikiran masingmasing dalam memecahkan masalah bersama. ${ }^{3}$ Diskusi kelompok merupakan

${ }^{3}$ Moh. Surya (1975:107) 
suatu proses yang teratur yang melibatkan sekelompok orang dalam interaksi tatap muka yang informal, pengembangan kesimpulan atau pemecahan masalah. ${ }^{4}$

\section{Jenis-jenis diskusi ${ }^{5}$}

a. Whole group (lecture discussion) Adalah diskusi kelompok utuh dimana kelas di modifikasi menjadi satu kelompok dengan posisi dosen berada di hadapan suatu kelas dan memberi informasi serta pertanyaan kepada para mahasiswa dan mahasiswa juga mengambil bagian dengan menjawab pertanyaan. Kelas whole group lebih ideal apabila jumlah anggotanya tidak lebih dari 15 orang.

b. Buzz group

Suatu kelompok besar dibagi menjadi beberapa kelompok kecil, terdiri atas 45 mahasiswa. Tempat di atur agar mahasiswa dapat berhadapan muka dan bertukar pikiran dengan mudah. Diskusi dilakukan di tengah atau di akhir pelajaran dengan maksud menajamkan bahan pelajaran atau menjawab pertanyaan-pertanyaan.

c. Panel (round table discussion)

Suatu kelompok kecil, biasanya 3-6 mahasiswa. Mendiskusikan satu objek tertentu, duduk dalam susunan semi melingkar, dipimpin oleh satu moderator.

d. Syndicate group

Suatu kelompok kecil yang terdiri dari 3-6 mahasiswa. Masing-masing kelompok kecil melakukan tugas-tugas tertentu. Dosen menjelaskan garis besar

\footnotetext{
${ }^{4}$ Moh. Uzer Usman (2005:94)

${ }^{5}$ http://ekaapriliyanti.blogspot.com/2011/12/ model-pembelajaran-diskusi-kelas.html online 03 maret 2019.
}

suatu masalah. Kemudian tiap-tiap kelompok diberi tugas untuk mempelajari suatu aspek tertentu.guru menyegiakan referensi dan informasi.

e. Brainstorming group

Merupakan diskusi uraian pendapat, dimana setiap kelompok menyumbangkan ide-ide baru tanpa dinilai segera.

f. Symposium

Merupakan diskusi dimana beberapa mahasiswa membahas tentang berbagai aspek dari sebuah objek tertentu, dan membacakan di depan kelas secara singkat (5-20 menit), kemudian di ikuti dengan sanggahan dan pertanyaan dari para pemdengar.

g. Colloquium

Merupakan diskusi dimana seseorang atau sumber menjawab pertanyaan dari mahasiswa, dan mahasiswa melakukan wawancara terhadap orang atau sumber tersebut.

h. Informal debate

Yaitu diskusi yang di lakukan dimana mahasiswa berhadapan satu sama lain dan membahas perdebatan yang bersifat problematika bukan yang bersifat actual.

i. Fish bowl

Mahaiswa di bagi menjadi beberapa kelompok, yang disebut sebagai (kelompok dalam) mendiskusikan suatu masalah tertentu, dan kelompok lainnya (kelompok luar) sebagai pendengar.

\section{Kelebihan Metode Diskusi}

a. Melatih mahasiswa belajar untuk mengemukakan pemikiran dan pendapat menggunakan bahasa asing (bahasa Inggris). 
b. Memberikan kesempatan mahasiswa untuk memperoleh penjelasanpenjelasan dari berbagai sumber.

c. Memberi kesempatan mahasiswa dapat menyelesaikan problem bersamasama.

d. Melatih mahasiswa untuk berdiskusi di bawah asuhan dosen menggunakan bahasa asing (bahasa Inggris).

e. Merangsang mahasiswa untuk ikut mengemukakan pendapat sendiri menyetujui atau menentang pendapat teman-teman.

f. Mengembangkan rasa solidaritas/ toleransi terhadap pendapat yang bervariasi.

g. Melatih mahasiswa untuk dapat berfikir secara matang-matang sebelum berbicara.

h. Melatih mahasiswa berbicara secara sistematis menggunakan bahasa asing (bahasa Inggris).

i. Menambah wawasan mahasiswa terhadap problem yang di bahas.

\section{Kekurangan metode diskusi}

a. Tidak semua topik dapat di jadikan metode diskusi hanya hal-hal yang bersifat problematik saja yang dapat didiskusikan.

b. Diskusi yang mendalam memerlukan banyak waktu.

c. Sulit menuntukan batas luas atau kedalaman suatu uraian diskusi.

d. Biasaanya tidak semua mahasiswa berani menyatakan pendapat, aplagi menggunakan bahasa asing (bahasa Inggris).

e. Pembicaraan di dalam diskusi lebih di domonasi oleh mahasiswa yang berani, yang banyak memiliki hafalan kosa kata bahasa asing (bahasa Inggris) dan telah terbiasa bicara didepan umum.

f. Memungkinkan munculnya rasa permusuhan antar kelompok,dan menganggap kelompoknyalah yang paling benar.

\section{Kualitas}

Sering kita menggunakan kualitas di sisipkan di setiap pembicaraan Anda untuk menunjukkan sebagai salah satu tolak ukur dalam sesuatu hal. Kualitas atau mutu adalah tingkat baik buruknya atau taraf atau derajat sesuatu. Istilah ini banyak digunakan dalam dalam bisnis, rekayasa, dan manufaktur dalam kaitannya dengan teknik dan konsep untuk memperbaiki kualitas produk atau jasa yang dihasilkan, seperti Six Sigma, TQM, Kaizen, dll. ${ }^{6}$

Goestch dan David mengungkapkan Kualitas merupakan suatu kondisi dinamis yang berhubungan dengan produk, jasa, manusia, proses dan lingkungan yang memenuhi atau melebihi harapan. ${ }^{\text {? }}$

\section{Berbicara (speaking)}

Berbicara merupakan suatu bentuk perilaku manusia yang memanfaatkan faktor-faktor fisik, psikologis, neurologis, semantis dan linguistik yang sangat intensif. ${ }^{8}$ Sementara Brown dan Yule dalam Nunan berpendapat bahwa berbicara adalah menggunakan bahasa lisan yang terdiri dari ucapan yang pendek, tidak utuh atau terpisah-pisah dalam lingkup pengucapan. Pengucapan tersebut sangat erat berhubungan dengan hubungan timbal

\footnotetext{
${ }^{6}$ https://goblognyaandi.wordpress.com/2012/ 09/30/definisi-kualitas-ringkasan/

${ }^{7}$ Goestch dan David (1994)

${ }^{8}$ Henry Guntur Tarigan 1981. Berbicara Sebagai Suatu Keterampilan Berbahasa.Bandung: Angkasa.
} 
balik yang dilakukan antara pembicara satu dengan pendengar. ${ }^{9}$

Sedangkan menurut Djago Tarigan berbicara adalah keterampilan menyampaikan pesan melalui bahasa lisan. Kaitan antara pesan dan bahasa lisan sebagai media penyampaian sangat berat. Pesan yang diterima oleh pendengar tidaklah dalam wujud asli, tetapi dalam bentuk lain yakni bunyi bahasa. Pendengar kemudian mencoba mengalihkan pesan dalam bentuk bunyi bahasa itu menjadi bentuk semula. ${ }^{10}$

Tujuan umum berbicara menurut Djago Tarigan terdapat beberapa golongan yakni: ${ }^{11}$

a. Menghibur Berbicara

$\mathrm{Si}$ pembicara menarik perhatian pendengar dengan berbagai cara, seperti humor, spontanitas, menggairahkan, kisah-kisah jenaka, petualangan, dan sebagainya untuk menimbulkan suasana gembira pada pendengarnya.

b. Menginformasikan

Melaporkan dan dilaksanakan bila seseorang ingin:

1) menjelaskan suatu proses;

2) menguraikan, menafsirkan, atau menginterpretasikan sesuatu hal;

3) memberi, menyebarkan, atau menanamkan pengetahuan;

4) menjelaskan kaitan.

c. Menstimulasi Berbicara

Berbicara itu harus pintar merayu, mempengaruhi, atau meyakinkan

${ }^{9}$ David Nunan, 1989. Designing Task for the Communicative Classroom. Cambridge: Cambridge University Press.

${ }^{10}$ Djago Tarigan, 1995. Materi Pokok Pendidikan Bahasa Indonesia. Jakarta: Depdikbud.

${ }^{11}$ Ibid pendengarnya. Ini dapat tercapai jika pembicara benar-benar mengetahui :

1) kemauan,

2) minat,

3) inspirasi,

4) kebutuhan, dan

5) cita-cita pendengarnya.

d. Menggerakkan Dalam berbicara

Untuk menggerakkan diperlukan pembicara yang berwibawa, panutan atau tokoh idola masyarakat. Melalui kepintarannya dalam berbicara, kecakapan memanfaatkan situasi, ditambah penguasaannya terhadap ilmu jiwa massa, pembicara dapat menggerakkan pendengarnya.

\section{Ragam Bentuk Berbicara}

Secara garis besar bentuk berbicara dibagi dalam beberapa bentuk, yaitu:

a. Berbicara di muka umum

Menurut Tarigan beberapa kegiatan berbicara ke dalam kategori tersebut. ${ }^{12}$

1) Berbicara dalam situasi yang bersifat memberitahukan atau melaporkan, bersifat informatif (informative speaking).

2) Berbicara dalam situasi yang bersifat membujuk, mengajak, atau meyakinkan (persuasive speaking).

3) Berbicara dalam situasi yang bersifat merundingkan dengan tenang dan hati-hati (deliberate speaking).

b. Berbicara dalam konferensi

1) Kelompok resmi (formal),

2) Kelompok tidak resmi (informal)

${ }^{12}$ Henry Guntur Tarigan 1981. Berbicara Sebagai Suatu Keterampilan Berbahasa.Bandung: Angkasa, hal. 22-23. 
c. Prosedur Parlementer

Berdebat

1) Debat parlementer atau majelis,

2) Debat pemeriksaan ulangan,

3) Debat formal, konvensional atau debat pendidikan.

Aktifitas dalam keterampilan

berbicara oleh Richards dan Renandya dibagi dalam empat aktivitas: ${ }^{13}$

a. Lisan (aural: oral activities),

b. Gambar (visual: oral activities),

c. Bantuan material (material-aided: oral activities), dan

d. Kesadaran budaya (culture awareness: oral activities).

\section{Fungsi Berbicara}

Menurut Richards fungsi berbicara antara lain: ${ }^{14}$

a. Sebagai interaksi (talk as interaction)

Unsur pokoknya antara lain:

1) berfungsi sosial,

2) Merefleksikan hubungan,

3) Merefleksikan identitas pembicara,

4) Bisa jadi formal atau casual,

5) menggunakan syarat percakapan,

6) Merefleksikan tingkat kesopanan,

7) Menggunakan kata-kata generik,

8) Menggunakan percakapan terdaftar/resmi,

9) Terkonstruksi bersama.

b. Sebagai transaksi (talk as transaction)

Unsur pokoknya antara lain:

1) Fokus pada informasi,

2) Berfokus pada psan dan bukan pada partisipan,

${ }^{13}$ J. C. Richards, dan W. A. Renandya, 2002. Methodology in Language Teaching: An Anthology of Current Practices. New York: Cambridge University Press.

${ }^{14}$ Jack C. Richards, 2008. Teaching Listening and Speaking From Theory to Practice. London: Cambridge University Press
3) Menggunakan strategi komunikasi agar bisa dipahami,

4) Ada pertanyan, pengulanghan dan pemahaman,

5) Ada negosiasi,

6) Akurasi linguistik tidak begitu penting.

c. Sebagai kinerja/publik (talk as performance)

Unsur pokoknya antara lain:

1) Fokus pada pesan dan audiens,

2) Penyusunan dan kata berurut,

3) Memenitngkan akurasi dan bentuk,

4) Cenderung bahas tulisan,

5) Sering dalam bentuk monologik.

\section{Faktor-faktor yang Mempengaruhi Efektivitas Berbicara}

Menurut Arsjad dan Mukti mengemukakan bahwa untuk menjadi pembicara yang baik, seorang pembicara harus menguasai masalah yang sedang dibicarakan, dan harus berbicara dengan jelas dan tepat. Beberapa faktor yang harus diperhatikan oleh pembicara untuk keefektifan berbicara adalah $:^{15}$

a. Faktor kebahasaan

Faktor kebahasaan yang menunjang keefektifan berbicara, meliputi:

1) Ketepatan ucapan, pengucapan buyi-bunyian harus tepat, begitu juga dengan penempatan tekanan, durasi, dan nada yang sesuai.

2) Pemilihan kata atau diksi, harus jelas, tepat dan bervariasi sehingga dapat memancing kepahaman dari pendengar.

\footnotetext{
${ }^{15}$ Maidar G Arsjad, dan U.S. Mukti, 1988. Pembinaan Kemampuan Berbicara Bahasa Indonesia. Jakarta: Erlangga.
} 
3) Ketepatan sasaran pembicara, pemakaian kalimat atau keefektivan kalimat memudahkan pendengar untuk menangkap isi pembicaraan.Penilaian dari faktor kebahasaan meliputi:
a) Ucapan,
b) Tata bahasa,
c) Kosa kata,

b. Faktor non kebahasaan

1) Sikap yang tidak kaku

2) Kesediaan menghargai pendapat,

3) Pandangan ke pendengar,

4) Gerak-gerik atau mimik tepat,

5) Kenyaringan suara,

6) Kelancaran berbicara,

7) Penguasaan topik.

Penilaian dari faktor non kebahasaan meliputi:
a) ketenangan,
b) volume suara,
c) Kelancaran,
d) pemahaman.

\section{Kesimpulan}

Dari penjelasan diatas penulis mengambil kesimpulan bahwa betapa pentingnya kita mengetahui cara berinteraksi, berdialog/berdiskudi dengan baik, baik itu didepan publik, forum yang formal maupun non formal. Selain penguasaan emosi, penguasaan materi juga diutamakan. Sehingga rasa percaya diri kita bisa terkontrol. Karena bahasan ini mengenai penggunaan bahasa asing (bahasa Inggris) dalam diskusi maka kosakata juga harus diutamakan agar bisa menjadi tolak ukur kualitas seseeorang/kelompok yang nantinya diharapkan bisa menghasilkan kualitas yang lebih baik dari sebelumnya karena telah menggunakan metode class discussion berbahasa asing.

Ada banyak jenis, ragam, fungsi dan faktor yang bisa menjadi acuan dalam hal berbicara (speaking) agar ketika penyampaian argument, statement dll bisa dengan baik keluar dari seseorang yang menyampaikan serta mudah difahami oleh seluruh penyimak.

\section{DAFTAR PUSTAKA}

Arsjad, Maidar G dan Mukti, U.S. 1988. Pembinaan Kemampuan Berbicara Bahasa Indonesia. Jakarta: Erlangga.

Goestch dan David (1994)

Henry Guntur Tarigan. 1981. Berbicara Sebagai Suatu Keterampilan Berbahasa. Bandung: Angkasa.

Nunan, David. 1989. Designing Task for the Communicative Classroom. Cambridge: Cambridge University Press.

Richards, J. C. dan Renandya W. A., 2002. Methodology in Language Teaching: An Anthology of Current Practices. New York: Cambridge University Press.

Richards, Jack C. 2008. Teaching Listening and Speaking From Theory to Practice. London: Cambridge University Press

Surya, Moh. (1975:107)

Tarigan, Djago. 1995. Materi Pokok Pendidikan Bahasa Indonesia. Jakarta: Depdikbud. 
Tarigan, Henry Guntur. 1981. Berbicara Sebagai Suatu Keterampilan Berbahasa. Bandung: Angkasa, hal. 22-23.

Usman, Moh. Uzer. (2005:94)

\section{WEBSITE}

https://goblognyaandi.wordpress.co $\underline{\mathrm{m} / 2012 / 09 / 30 / \text { definisi-kualitas-ringkasan/ }}$ http://ekaapriliyanti.blogspot.com/2011/12/ model-pembelajaran-diskusi-kelas.html online 03 maret 2019 
Metode Pembelajaran Class Discussion Dapat Meningkatkan Kualitas Speaking (Bahasa Inggris) Terhadap Mahasiswa/Peserta Didik 